\section{P-glycoprotein in the developing human blood-brain barrier}

To the Editor: The recent publication by Lam and colleagues titled "The Ontogeny of P-glycoprotein in the Developing Human Blood Brain Barrier: implication for opioid toxicity in neonates" (1) was of keen interest. In a prior study, the ontogeny of P-glycoprotein (P-gp/ABCB1) in the human central nervous system was characterized not only by a marked progressive increase in $\mathrm{P}$-gp/ABCB1 immunostaining in microvascular endothelial cells between 22 and $42 \mathrm{wk}$ gestation but also by differential staining intensity between the hindbrain/thalamus and regions of the forebrain and neocortex (2). Given that opiates affect the brainstem, cerebellum, midbrain, and cortex, did the authors of the current study explore potential subcortical and/or regional differences in P-gp/ABCB1 immunoreactivity that might be germane to understanding opioid effects in the developing central nervous system? In this regard, the developmental increase of human microvascular endothelial cell P-gp/ABCB1 immunostaining mirrors that of murine studies showing marked perinatal (3), early postnatal (4), and late postnatal (5) increases in central nervous system microvessel
P-gp expression and suggests that murine models may be helpful in studying the developmental effects of P-gp expression on central nervous system morphine pharmacodynamics.

\section{STATEMENT OF FINANCIAL SUPPORT}

No financial assistance was received to support this letter.

Disclosure: No conflict of interest to disclose.

\section{Jon F. Watchko'}

${ }^{1}$ Division of Newborn Medicine, Department of Pediatrics, University of Pittsburgh School of Medicine, Pittsburgh, Pennsylvania.

Correspondence: Jon F. Watchko (jwatchko@mail.magee.edu)

\section{REFERENCES}

1. Lam J, Baello S, Iqbal M, et al. The ontogeny of P-glycoprotein in the developing human blood-brain barrier: implication for opioid toxicity in neonates. Pediatr Res 2015;78:417-21.

2. Daood M, Tsai C, Ahdab-Barmada M, Watchko JF. ABC transporter (P-gp/ABCB1, MRP1/ABCC1, BCRP/ABCG2) expression in the developing human CNS. Neuropediatrics 2008;39:211-8.

3. Tsai CE, Daood MJ, Lane RH, Hansen TW, Gruetzmacher EM, Watchko JF. P-glycoprotein expression in mouse brain increases with maturation. Biol Neonate 2002;81:58-64.

4. Matsuoka Y, Okazaki M, Kitamura Y, Taniguchi T. Developmental expression of P-glycoprotein (multidrug resistance gene product) in the rat brain. J Neurobiol 1999;39:383-92.

5. Rosati A, Maniori S, Decorti G et al. Physiological regulation of P-glycoprotein, MRP1, MRP2, and cytochrome P450 3A2 during rat ontogeny. Develop Growth Differ 2003;45:377-87. 